\title{
Tip of the Tongue dalam Ujaran Penutur Asing Bahasa Indonesia: Studi Kasus Mahasiswa BIPA
}

FIDA PANGESTI

fidapangesti@umm.ac.id

ARTI PRIHATINI

artiprihatini@umm.ac.id

Program Studi Pendidikan Bahasa Indonesia, Universitas Muhammadiyah Malang

Malang, Indonesia

dikirim: 16/2/2020 diperbaiki: 9/11/2020 diterima: 12/11/2020 DOI: 10.22515/ljbs.v5i2.2200 hlm: 201-211

ABSTRACT Tip of the tongue (ToT) is experienced by BIPA students when speaking Indonesian due to delayed lexical access. This study aims to describe two focuses, namely: (1) the characteristics of the target vocabulary and the ToT vocabulary and (2) the mental processes when the ToT occurs. The theory used in this research is lexical retrieval in morphosemantics. This research method is descriptive qualitative. Data collection was carried out by observation and interview techniques during the learning process of BIPA Muhammadiyah Malang University. The results showed that ToT occurred in nouns (42\%), verbs $(24 \%)$, adjectives (21\%), conjunctions ( $8 \%)$, and numeralia $(5 \%)$. Tip of the tongue is accompanied by a lot of silence as a fallacy effect that appears in the speech. Gestur becomes a description of the meaning features of the target vocabulary. The mental process of TOT occurs in several events, namely (1) the speaker has a picture of the object in his mind, (2) the activation of the semantic set when the active vocabulary has a relation with the meaning of the target vocabulary, (3) activation of the meaning field when the speaker describes it, (4) activation of the phonological set when the similar sound vocabulary appears in the mind, and (5) the appearance of the first language and / or intermediate language.

Keywords: bahasa Indonesia, foreign speaker, tip of the tongue

PENDAHULUAN Proses produksi bahasa diawali dengan penentuan gagasan yang akan disampaikan. Proses itu disebut dengan representasi semantikatau lexical retrieval. Kata dapat di-retrieve dengan memanfaatkan dua informasi, yaitu informasi makna dan informasi bunyi. Penutur harus me-retrieve kata yang mengandung makna yang tepat dan sesuai dengan struktur kalimat yang dihasilkan (Fernandez \& Cairns 2011, 141). Berkaitan dengan hal itu, Pinet \& Nozari (2018) juga menjelaskan bahwa proses produksi bahasa melalui beberapa tahap, yaitu sebuah pesan perlu disusun, kata yang tepat perlu dipilih, ketepatan pengucapan perlu diingat, dan suasana yang tepat perlu dipertimbangkan dengan mempertimbangkan urutan tuturan yang sesuai.

Akan tetapi, dalam proses produksi bahasa tersebut, fase akses leksikal tak jarang mengalami kendala. Beragam faktor dapat melatarbelakangi munculnya kendala tersebut, seperti gugup, ragu-ragu, tertekan, dan sebagainya. Kendala akses leksikal yang biasa dialami adalah penutur hendak mengucapkan suatu kata, tetapi mengalami kendala sementara sehingga kata tersebut belum berhasil diingat. Fenomena tersebut disebut dengan tip of the tongue. Calabi $(2016,409)$ mengemukakan bahwa ToT terjadi ketika ada kegagalan retrieval kata. Secara lebih spesifik, Radel \& Fournier (2017, 12-18) serta Kozlovskiy $(2017,218)$ menjelaskan bahwa tip of the tongue terjadi ketika seseorang gagal me-retrieve sebuah kata meskipun tahu betul bahwa kata tersebut sebenarnya sudah ia ketahui dan ia simpan dalam memorinya sehingga dapat menyebutkan beberapa informasi tentang kata tersebut, seperti asosiasi kata, huruf pertama, jumlah suku kata, dan sebagaimana. Berkaitan dengan hal itu, Fernandez \& Cairns $(2011,143)$ juga menyatakan bahwa seseorang yang mengalami tip of the tongue mengetahui ciri-ciri kata 
yang belum berhasil diingat tersebut, seperti bunyi awal atau akhir, huruf awal atau akhir, jumlah suku kata, penekanan suku kata yang diucapkan, dan kemiripan kata tersebut dengan kata yang lain.

Berkaitan dengan hal itu, Schwartz $(2008,9)$ menjelaskan bahwa ToT terjadi ketika penutur merasa mengetahui suatu kata yang hendak diucapkannya tetapi ia belum berhasil mengingat kata tersebut, sedangkan perasaan mengetahui kata tersebut berisi prediksi terhadap kata yang perlu diingatnya itu. Untuk memprediksi kata yang perlu diingat itu, Singleton $(2000,162)$ menentukan beberapa indikator sebagai berikut:

1. mengetahui pengucapan kata agar orang tersebut dapat mengenali dan memproduksi kata tersebut dalam tutura;n

2. mengetahui penulisan kata agar orang tersebut dapat mengenali dan memproduksi kata tersebut dalam tulisan;

3. mengetahui makna kata agar orang tersebut dapat memahami dan memanfaatkan kata tersebut secara tepat;

4. mengetahui perilaku morfologis kata agar orang tersebut dapat mengenali dan menggunakan kata tersebut dalam berbagai bentuk yang berbeda (tunggal, jamak, dsb);

5. mengetahui perilaku sintaktis kata agar orang tersebut dapat mengidentifikasi fungsinya dalam frasa dan kalimat dan agar dapat menggunakannya dengan berbagai peran yang berbeda dalam frasa dan kalimat.

Hasil observasi menunjukkan bahwa ToT juga dialami penutur asing bahasa Indonesia, dalam hal ini mahasiswa BIPA (Bahasa Indonesia bagi Penutur Asing). Hal itu dapat dilihat pada tuturan berikut:

Kalau pacar itu putus. Kalau menikah itu ce.. ce.. ce.. ceria apa? Ceria. Oh, no, no, no ceria. Apa?

Tuturan di atas menunjukkanToT yang dialami oleh mahasiswa BIPA. Penutur dapat mengetahui kosakata target yang diinginkan, yaitu kata cerai. Hal itu dibuktikan dengan munculnya 'kalau menikah' sebagai kata kunci terhadap makna kosakata target. Akan tetapi, penutur tidak dapat mengingat dengan tepat kosakata target itu melainkan hanya mengingat bunyi awal yaitu ' $c$ ', silabel awal yaitu 'ce' dan komposisi bunyi dalam kosakata target yaitu 'c-e-r-i-a'. Fakta ini sejalan dengan pandangan Gollan \& Silverberg (2001) yang menyatakan bahwa ToT lebih banyak terjadi pada penutur yang bilingual daripada monolingual. Hal itu membuat penelitian ToT dalam produksi bahasa penutur asing bahasa Indonesia menjadi menarik untuk diteliti, terlebih untuk melihat lebih jauh karakteristik khusus ToT pada penutur asing bila dibandingkan dengan ToT pada penutur asli.

Berdasarkan uraian tersebut, penelitian mengenai tip of the tongue dalam ujaran penutur asing bahasa Indonesia menjadi menarik untuk dilakukan. Berkaitan dengan penelitian ini, terdapat beberapa penelitian yang relevan. Penelitian Ecke (2004) menemukan bahwa penutur bilingual mengalami lebih banyak ToT pada kata-kata dalam salah satu bahasa yang penggunaannya kurang dominan. Penelitian Schwartz (2008) menemukan bahwa judgment metakognitif positif berpengaruh terhadap performansi working memory, mendukung gagasan yang digunakan working memory dan metamemori dalam proses monitor selama ToT. Selain itu, Schwartz juga menemukan bahwa ToT dan feeling of knowing judgment (FOKs) merupakan entitas metakognitif yang terpisah. Selain itu, Schwartz (2010) meneliti pengaruh emosi terhadap ToT. Schwartz menemukan bahwa pelibatan emosi 
mendorong munculnya ToT. Penelitian Ecke \& Hall (2013) yang dilakukan terhadap penutur multilingual secara longitudinal menemukan bahwa tingkat status ToT dan persentase asosiasi kata lintas-bahasa dan asosiasi kata dalam-bahasa berfluktuasi sebagai respons terhadap pola dinamis penggunaan dan pemeliharaan bahasa.

Selain itu, terdapat dua penelitian ToT yang dilakukan dalam konteks Indonesia. Penelitian pertama dilakukan Afrilia (2015) yang berjudul Tip of The Tongue pada Penutur Bahasa Indonesia dan Implikasinya Terhadap Model Akses Leksikal. Sejalan dengan judulnya, penelitian ini mengkaji pengalaman ToT) pada penutur bahasa Indonesia dan pengaruh kompleksitas fonotaktik terhadap kejadian ToT, serta implikasinya terhadap model akses leksikal. Hasil penelitian menjelaskan bahwa: (1) fitur-fitur generic recall yang muncul pada ToT bahasa Indonesia adalah fitur relasi makna, definisi, dan memori episodik pada level konseptual; dan fitur segmen awal, segmen tengah, segmen akhir, jumlah suku kata, dan kemiripan fonologis pada level leksem; (2) variabel kompleksitas fonotaktik menjadi salah satu faktor yang mempengaruhi probabilitas kejadian ToT; (3) model akses leksikal yang paling banyak muncul pada proses akses leksikal bahasa Indonesia adalah model serial; dan (4) kecenderungan kemunculan model serial terjadi pada kedua kelompok pola fonotaktik.Penelitian kedua dilakukan oleh Rahman, Kushartanti, dan Anjarningsih (2017) dengan judul Tip of The Tongue Analysis in Indonesian Language Speaker: A Case Study. Penelitian ini bertujuan untuk menjelaskan tingkatan retrieval kata yang memungkinkan terjadinya ToT pad apenutur Indonesia. Hasil penelitian menunjukkan bahwa penutur Indonesia mengalami ToT pada level kata, suku kata, maupun huruf.

Meskipun sama-sama mengkaji ToT, penelitian ini berbeda dengan penelitian sebelumnya dalam dua hal. Pertama, penelitian sebelumnya mengkaji ToT pada bahasa Indonesia yang dituturkan oleh penutur asli Indonesia, sementara penelitian ini mengkaji ToT yang dialami oleh penutur asing yang berbahasa Indonesia. Kedua, penelitian sebelumnya menggunakan desain penelitian eksperimental, sementara penelitian ini menggunakan desain penelitian naturalistik. Berdasarkan latar belakang tersebut, perlu dilakukan penelitian yang terfokus pada dua hal, yaitu: (1) karakteristik kosakata target dan kosakata ToT, serta (2) proses mental dalam peristiwa ToT.

METODE Jenis penelitian ini adalah deskriptif-kualitatif. Mahsun (2012) menegaskan PENELITIAN bahwa penelitian kualitatif berfokus pada penunjukan makna, deskripsi, penjernihan, dan penempatan data pada konteksnya masing-masing. Data penelitian berupa kosakata target dan kosakata ToT serta proses mental ketika ToT terjadi. Sumber data penelitian yaitu UPT BIPA Universitas Muhammadiyah Malang. Adapun subjek penelitiannya yaitu 15 mahasiswa BIPA UMM pada jenjang dasar dan menengah yang berasal dari Thailand, Vietnam, Sierra Lione, Afghanistan, Palestina, Korea Selatan, dan Jepang. Pemilihan subjek penelitian ini dilakukan dengan teknik purposive sampling dengan asumsi semakin rendah level berbahasa penutur makan semakin banyak terjadi ToT. Teknik pengumpulan data menggunakan observasi, yakni mengamati praktik berbicara bahasa Indonesia selama pembelajaran di BIPA UMM. Selain observasi, wawancara juga dilakukan terhadap mahasiswa yang mengalami ToT untuk menggali informasi tentang proses mental yang dialami ketika mengalami ToT. Selanjutnya, data dianalisis dengan mengacu 
pada teori ToT Schwartz (2008). Kegiatan analisis ini dilakukan dengan tahapan (1) mengidentifikasi ujaran yang mengandung ToT; (2) mengidentifikasi kosakata ToT; (3) mengidentifikasi kosakata target; (4) menganalisis hubungan antara kosakata ToT dan kosakata target; serta (5) menganalisis proses mental ketika ToT.

HASIL Tip of the tongue pada dasarnya dapat terjadi pada hampir semua kelas kata. Berikut datanya.

\section{Karakteristik ToT dalam Tuturan Pembelajar BIPA}

Kelas kata ToT
(1) Saya kaget sekali karena ada tikus berlari dari pintu ke bawah karsus saya. (diam 3 detik). Kaaaruu.. Karus.. Ah, kaasur. Ya, kasur!

(2) Ibu saya bilang saya ke Indonesia untuk be..be.. bee.. cck learn bahasa Indonesia saja. Tidak bisa untuk punya istri.

(3) Saya suka tinggan [tinggal] di sini karena semua orang marah, bukan bukan bukan marah. Suka tersenyum. Ra... ramah!

(4) Sebenarnya saya suka tinggal di Bali, tetapi di sana panas sekali. Jika... eerr..apa? Eerr.. Jadi, maksud saya jadi. Jadi, mungkin saya ke sana untuk berlibur saja. Tidak mau untuk tinggal di sana.

(5) Itu mahal sekali. Saa... ee...apa ya? 1 million 1 million.

Data (1) hingga (5) di atas merepresentasikan tuturan yang mengandung tip of the tongue. Pada data (1), penutur sedang menjelaskan pengalaman tidak menyenangkan yang dialaminya kemarin di kos. Ada tikus yang masuk ke kamarnya melewati pintu dan berlari ke bawah kasur. Kosakata target dalam ToT ini adalah 'kasur'. Akan tetapi, dalam proses recall kata 'kasur', penutur mengalami kendala. Hal itu terlihat dari munculnya 'karu' serta 'karus' yang diucapkan dengan pemanjangan. Setelah beberapa saat, penutur akhirnya dapat mengakses kosakata target yang dibutuhkannya. Dalam hal ini, kosakata target dalam data (1) berkelas kata nomina.

Data (2) muncul dalam kelas berbicara dengan tema rencana masa depan. Pebelajar menyampaikan bahwa dalam 5 tahun ke depan rencana hidupnya adalah menikah. Pada saat guru bertanya tentang apakah berkeinginan memiliki istri orang Indonesia, pembelajar menjawab bahwa ia ingin tetapi tidak bisa karena ibunya sudah memperingatkan bahwa ia datang ke Indonesia untuk belajar saja. Dalam mengakses kata 'belajar' inilah, pembelajar mengalami kendala. Penutur lupa kosa kata target tersebut dan hanya mengingat bahwa silabel awalnya adalah 'be-'. Oleh karena frustasi tidak dapat mengingat kosakata sasaran, pebelajar menyerah dan memutuskan untuk menyebutkan kosakata dalam bahasa Inggris yakni learn.

Data (3) dan (4) muncul dalam kelas tata bahasa dengan tema kota favorit. Dalam data (3), pebelajar menjelaskan bahwa kota favoritnya adalah Malang karena warganya ramah. Adapun dalam data (4), pebelajar menjelaskan bahwa kota favoritnya adalah Bali. Akan tetapi, karena Bali sangat panas, dia hanya ingin singgah saja di sana. Dalam hal ini, pembelajar mengalami tip of the tongue dalam mengakses kosakata target berkelas kata adjektiva 'ramah' (data 3) dan kosakata target berkelas kata konjungsi 'jadi' (data 4). Data 4 mengandung penanda pemintaan yang dinegasikan sebagaimana tampak pada kalimat Tidak mau tinggal di sana. Hodairiyah \& Utama $(2019,15)$ menemukan bahwa kata 'mau' adalah penanda kalimat imperatif permintaan.Jadi, kalimat tersebut bermakna imperatif permintaan yang dinegasikan.

Adapun dalam data (5), penutur mengalami tip of the tongue dalam mengakses kata sejuta. Kemunculan data tersebut dilatari konteks 
penceritaan harga kos di Kota Malang saat ini. Penutur menjelaskan bahwa ia ingin pindah kos, tetapi saat ini kos di Kota Malang mahal sekali, mencapai harga sejuta. Dalam hal ini, penutur hanya mengingat bunyi awal kosakata target yakni $s$. Sebagaimana pebelajar dalam data (2), pebelajar dalam data (5) ini menyerah saat tidak dapat dengan segera mengakses kosakata target dan memutuskan untuk menggunakan bahasa Inggris 1 million. Dengan demikian, kosakata target dalam data ini adalah kata bilangan.

Berdasarkan paparan di atas, dapat dipahami bahwa tip of the tongue dapat terjadi pada hampir semua kelas kata. Kelas kata tersebut meliputi kata benda, kata kerja, kata sifat, kata hubung, dan kata bilangan. Untuk selanjutnya, sebaran kelas kata kosakata target tip of the tongue dapat dilihat pada Diagram.

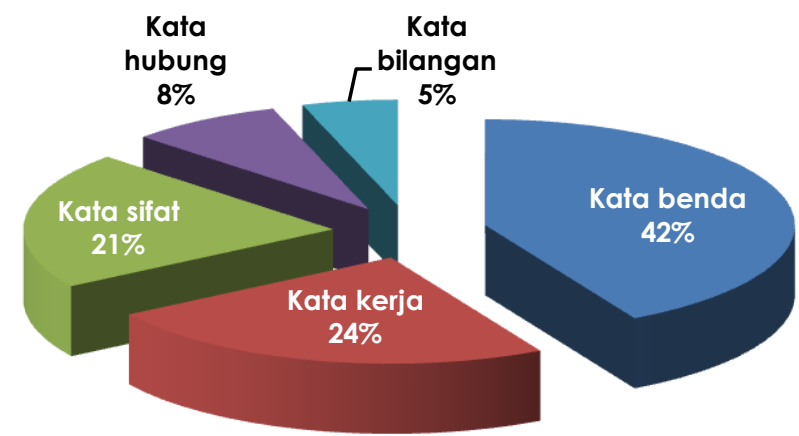

\section{Diagram: Distribusi kelas kata kosakata sasaran ToT dalam tuturan pembelajar BIPA}

ToT dan senyapan Dalam penelitian ini diperoleh fakta bahwa tip of the tongue dalam sebagian besar data muncul diiringi senyapan. Fraundorf \& Watson (2013) mendefinisikan senyapan sebagai bentuk gangguan verbal maupun nonverbal yang tidak berhubungan atau menjadi bagian dari pesan utama yang ingin disampaikan penutur. Senyapan ketidaklancaran ini hadir karena tiga alasan (Dardjowidjojo 2012, 144). Pertama, penutur senyap karena sudah terlanjur memulai ujarannya, tetapi sebenarnya belum siap untuk seluruh kalimat. Kedua, penutur lupa kata-kata yang dia perlukan. Ketiga, penutur berhati-hati dalam memilih kata agar tuturannya tidak berdampak negatif terhadap mitra tutur atau publik. Dengan demikian, tepatlah bila dikatakan bahwa hadirnya senyapan ketidaklancaran dalam tuturan menandai adanya kesulitan secara kognitif yang dialami penutur ketika bertutur. Untuk lebih jelasnya, dapat diperhatikan data berikut ini.

(6) A : Mas Rio satu angkatan dengan Mas Heu ya?

B : Tiddak.. Saya lebih lebiiiih... lebih tu..tua.

(7) Kalau tidak ada aktivitas, saya biasanya e..em.. apa? Apa? mee.. mendaki gunung.

Data (6) dan (7) di atas merepresentasikan tuturan yang mengandung tip of the tongue. Kosakata target data (6) yaitu 'tua', sementara kosakata target data (7) yaitu 'mendaki'. Dalam upaya me-recall kosakata target tersebut, penutur menggunakan senyapan. Dalam data (6), senyapan itu berupa pemanjangan dan pengulangan. Sementara itu, dalam data (7), senyapan itu berupa senyapan terisi berupa bunyi ' $e$ ' dan 'em', senyapan terisi berupa 
kalimat 'apa?', serta pemanjangan sekaligus pengulangan silabel 'me-'. Dalam konteks ini, senyapan ini digunakan untuk memperoleh tambahan waktu dalam mengakses kosakata sasaran.

ToT dan kilir lidah Dalam sebuah tuturan, sering ditemukan hal-hal sebagai berikut.

(8) Apakah saya bisa minum bukan bukan ma.. makan kue ini?

(9) Mbak, kenapa kamu ganteng (diam) e apa? Apa nama? Ce.. ce.. Apa? Ah! Beautiful. Kamu very beautifu/hari ini.

Dengan mencermati data-data di atas, dapat dipahami bahwa tip of the tongue muncul sebagai efek kekeliruan yang muncul dalam tuturan. Istilah khusus untuk kekeliruan ini adalah kilir lidah. Kilir lidah adalah suatu fenomena dalam produksi ujaran dimana pembicara 'terkilir' lidahnya sehingga kata-kata yang diproduksi bukanlah kata-kata yang dia maksudkan (Dardjowidjojo 2012,147).

Kilir lidah ini selanjutnya dapat dipilah menjadi dua, yaitu kilir lidah berupa kekeliruan seleksi kata-kata dan kilir lidah berupa kekeliruan assembling. Kekeliruan seleksi merupakan kekeliruan dalam proses pemilihan kata, sedangkan kekeliruan assembling adalah kekeliruan dalam menyusun kata-kata yang sudah dipilih dalam suatu konstruksi sintaksis (Dardjowidjojo 2012, 147-149). Dengan demikian, teranglah kiranya bahwa data (8) dan (9) di atas tergolong kilir lidah berupa kekeliruan seleksi.

Dalam data (8), penutur keliru dalam menyeleksi minum untuk makan. Kekeliruan itu terjadi saat pebelajar sedang berbincang dengan staf BIPA di kantor BIPA. Pada saat itu, penutur secara visual juga menyaksikan staf BIPA sedang minum air mineral. Hal itulah tampaknya yang membuat penutur keliru dalam menyeleksi kata. Dengan demikian, kekeliruan ini tergolong kekeliruan kontekstual, yaitu kekeliruan dimana unit-unit lingual sumber kekeliruan terdapat dalam konteks tuturan, baik lingual maupun ekstralingual (Kurniawati 2010). Selain itu, verba minum muncul sebelum menemukan verba makan disebabkan oleh hubungan semantik antara kedua verba yang menyatakan tindakan tersebut. Sebagaimana ditemukan Prihatini $(2019,440-$ 441) bahwa verba tindakan memiliki hubungan semantik yang dekat dengan verba tindakan pula.

Dalam data (9), penutur keliru dalam menyeleksi ganteng untuk cantik. Berbeda dengan data (8), kekeliruan dalam (9) ini terjadi karena kekeliruan dalam me-retrieve kata dalam satu medan semantik. Sebagaimana telah dipahami bersama, kata ganteng dan cantik tergolong dalam satu medan semantik yang sama, yaitu kata sifat penunjuk keelokan. Kekeliruan semacam ini tergolong kekeliruan non-kontekstual dan disebut Freudian Slips.

ToTdan gestur Gestur merupakan sebuah bentuk komunikasi nonverbal yang lazimnya mengiringi komunikasi verbal. Fungsi dari hadirnya gestur ini adalah sebagai penguat pesan atau pengganti komunikasi verbal. Demikian halnya, dalam konteks tip of the tongue, gestur menjadi realisasi deskripsi fitur makna yang dimiliki kosakata target. Untuk lebih jelasnya dapat dicermati data berikut.

(10) A : Ah, pahit sekali kopinya!

B : Oiya?

A : lya, pahit banget ini

B : Astaga iya..aduh, maaf.. Saya lupa me.. me.. (jari telunjuk menghadap ke bawah lalu berputar-putar). Aaah, apa namanya?

A : Mengaduk? 
B : lyaaaaaa... mengaduk. Saya lupa tidak mengaduk kopi itu tadi. Maaf!

Dalam data (10), penutur mengalami kesulitan dalam mengakses kosakata target 'mengaduk'. Dalam upaya menemukan kosokata target tersebut, penutur menggunakan gestur untuk memvisualisasikan atau mendeskripsikan kosakata target yang dimaksud. Oleh sebab itu, penutur menggunakan telunjuk lalu memutar-mutarnya. Melalui gestur ini pula, mitra tutur pada akhirmya dapat menebak bahwa kosakata target yang dibutuhkan penulis adalah 'mengaduk'.

Proses Mental dalam

Peristiwa ToT

Gambaran

objek dalam

pikiran

\section{Aktivasi \\ perangkat semantik}

Aktivasi medan makna
Berdasarkan focus group discussion (FGD), berikut adalah pernyataan pembelajar BIPA sebagai responden penelitian berkaitan dengan pengalaman Tip of the Tongue.

(11) Ketika saya lupa, saya imagine orang itu. Contoh kalau saya mau bicara 'Pak Arif' tapi saya lupa itu, saya seperti bisa lihat, / mean bisa bayangkan Pak Arif.

(12) I mostly draw in the air when I can not remember the word that I want because those are what I imagine in my mind.

Informasi di atas menunjukkan bahwa saat mengalami tip of the tongue, penutur memiliki gambaran objek dalam benaknya. Gambaran ini nyata, jelas, dan lazimnya berkaitan dengan nomina meski kosakata target bukan merupakan nomina. Sebagai contoh, kosakata target verba 'menari' memunculkan gambaran nomina persona yang sedang melakukan aktivitas tersebut, kosakata target adjektiva 'tinggi' akan memunculkan gambaran nomina persona atau benda—misalnya gedung atau pohon-yang tinggi.

(13) "Kenapa saya pikir kata minum waktu saya mau bilang makan? Kenapa ya? Itu aneh"

Data di atas menyatakan bahwa dalam ketika penutur mengalami ToT, kosakata yang lain juga ikut aktif. Dalam hal ini, kosakata yang aktif adalah kosakata yang memiliki keterkaitan makna dengan makna kosakata target. Dengan demikian, dapat dipahami bahwa saat mengalami ToT ada sebuah peristiwa aktivasi perangkat semantik. Hal ini dikarenakan sebuah kata pada dasarnya disimpan berdasarkan kriteria medan semantik (Dardjowidjojo 2012,171). Dalam medan semantik, kata-kata yang memiliki kesamaan fitur semantik disimpan dalam medan yang sama.

Pada dasarnya, setiap kosakata memiliki fitur makna atau acapkali disebut komponen makna dan medan makna. Wijana $(2010,48)$ menjelaskan bahwa komponen makna atau medan makna adalah ranah atau bidang arti yang dimiliki oleh butir-butir leksikal. Oleh sebab itu, tidaklah mengherankan apabila dalam pengalaman ToT, upaya yang dilakukan penutur untuk menemukan kosakata target adalah melalui pendeskripsian medan maknanya. Untuk lebih jelasnya, dapat dicermati data berikut ini.

(14) A : Kemarin saya bertemu Bu Rii, siapa ya? Rii.... Dia pakai kacamata

B : Bu Fini.

A : Oh, bukan bukan..Dia pakai jilbab juga tetapi bukan Ibu Fini. Dia kurus. Sedikit kecil. Aduh, siapa ya? Dia mengajar saya kelas menulis.

B : Oooh, ibu Rifa?

A : Yaaaa..! lya, Ibu Rifa. Kemarin saya bertemu dia di mall. 
Data di atas merepresentasikan kemundulan medan makna kosakata target ToT. Kosakata yang dimaksud adalah Ibu Rifa. Mengingat kosakata target adalah kata nama, maka medan makna yang muncul adalah ciri-ciri fisik dan informasi khusus terkait kosakata target. Hal itu dibuktikan dengan munculnya kata 'dia pakai kacamata', 'dia pakai jilbab', 'dia kurus', 'sedikit kecil', dan 'dia mengajar saya kelas menulis'.

(15) Sebenarnya saya bisa mendeskripsikan kosakata itu.

(16) Saya pakai definisinya karena mungkin saya pikir itu.

Data di atas merupakan hasil wawancara dengan informan. Informasi (1) dan (2) di atas memperkuat apa yang diuraikan sebelumnya terkait medan makna. Dalam (1) secara spesifik informan menyatakan dapat mendeskripsikan kosakata target. Adapun dalam (2), penutur menyatakan dapat mendefinisikan kosakata target. Berkaitan dengan itu, oleh karena hasil telaah medan makna dapat memberikan sumbangan bagi pendefinisian leksikon-leksikon terkait (Pangesti 2014), maka definisi itu sendiri merupakan akumulai fitur semantik medan maknanya.

Aktivasi Proses mental yang terjadi ketika penutur mengalami ToT berkaitan dengan perangkat penyimpanan kosakata dalam leksikon mental pada aspek kemiripan bunyi. fonologis Ketika penutur mengalami ToT, kosakata yang muncul dalam benak penutur adalah kosakata-kosakata yang memiliki kemiripan bunyi. Hal ini bisa dikonfirmasi melalui kemunculan data berikut ini.

(17) Ya, wanita yang di rumah sakit itu membantu saya. Apa nama dia? Pesawat, penawat, oh, perawat. Ya, perawat!

Tuturan (17) di atas merepresentasikan kemunculan ToT yang dialami penutur. Kosakata target penutur adalah 'perawat'. Namun, ketika hendak menggunakan kosakata tersebut, penutur tidak dapat dengan segera menemukan kosakatanya. Oleh sebab itu, penutur menggunakan ekspresi 'apa nama dia?'yang ketika dilihat dari konteksnya bukan merupakan pertanyaan literal meminta informasi kepada mitra tutur. Selanjutnya, dalam proses recal/kata itu, penutur menyebutkan kosakata 'pesawat' dan 'penawat' yang memiliki kemiripan bunyi dengan kosakata target. Dua kosakata yang dimunculkan memiliki jumlah silabel yang sama, bunyi awal yang sama, bunyi akhir yang sama, dan keseluruhan bunyi yang mirip. Fitur distingtifnya hanya berupa bunyi /s/, /n/, dan /r/. Paparan di atas diperkuat oleh hasil wawancara kepada informan sebagai berikut.

(18) Saya tadi ingat kata seperti dengan itu. Saya ingin bicara marah, but then di kepala saya kayak keluar kata murah, merah, meriah... ya itu.

Kemunculan Bagi penutur dwibahasa atau multibahasa, tidak dapat dipungkiri bahwa bahasapertama bahasa-bahasa yang dikuasainya pasti berkontribusi terhadap proses dan/atau perencanaan tuturan maupun tuturan itu sendiri. Dalam konteks bahasa antara pembelajaran BIPA ini, bahasa yang dimaksud dapat berupa bahasa pertama maupun bahasa antara. Bahasa antara adalah bahasa yang menjadi penjembatan antara bahasa pemelajar dengan bahasa sasaran. Lazimnya bahasa antara ini berupa bahasa Inggris. Hal itu terlihat dari data berikut.

(19) Oh, saya coba untuk ingat tapi enggak bisa. Saya hanya bisa like membayangkan itu. Dan, dan, dan saya.. Oh, tapi sangat ingat itu dalam bahasa negara saya.

(20) Saya lupa apa kata itu di bahasa Indonesia. Itu learn. Apa learn bahasa Indonesia? Itu bel...be..be.. apa? 
Tuturan (19) disampaikan oleh salah satu informan. Dalam kelas berbicara, ia mengalami ToT untuk kosakata target 'nakal'. Setelah pembelajaran berakhir, peneliti mewawancarai penutur sehingga diperoleh informasi bahwa penutur dapat mengingat kosakata target dalam bahasa pertama yakni bahasa Vietnam. Adapun dalam (20) RF secara eksplisit menyatakan bahwa yang muncul dalam benaknya ketika sedang mengalami ToT adalah bahasa antara (bahasa Inggris). Hal itu terlihat dari munculnya kata learn dalam tuturan tersebut.

PEMBAHASAN Kompleksitas perencanaan tuturan membuat produksi tuturan tidak selalu berjalan dengan baik dan menghasilkan tuturan yang ideal yang ditandai dengan kemunculan tip of the tongue. Hal ini terjadi pula pada penutur asing bahasa Indonesia. Bila dilihat pada aspek karakteristik kosakata terget, ToT terjadi pada hampir semua kelas kata, meliputi kata benda, kata kerja, kata sifat, kata hubung, dan kata bilangan. Namun, kuantitas kemunculan ToT yang paling tinggi adalah pada kata benda, terutama kata nama. Temuan ini sejalan dengan Schwartz $(2002,30)$ yang menyatakan bahwa tip of the tongue biasanya terjadi pada kata nama. Hal itu agaknya terjadi karena kata nama merupakan bagian yang penting dalam suatu tuturan. Kata nama sering kali menjadi hal pokok yang dibicarakan penutur dan memunculkan beragam penjelasan.

Di sisi lain, kemunculan ToT dalam beberapa kasus tidak lepas dari kemunculan kilir lidah. Penutur mengalami kekeliruan dalam mengakses leksikon dan tidak dapat dengan segera menemukan kosakata target sehingga terjadilah ToT. Dalam upaya menemukan kosataka target ini, penutur memanfaatkan senyapan ketidaklancaran tuturan untuk mendapatkan tambahan waktu. Hal itu sejalan dengan pernyataan GianicoRelyea \& Altarriba (2012, 764-765) yang menyatakan bahwa ketika mengalami ToT, kata-kata yang tidak sepenuhnya diingat biasanya bisa diselesaikan ketika diberikan waktu yang cukup. Di samping itu, penutur umumnya memanfaatkan gestur dengan tujuan mitra tutur dapat membantu menemukan kosakata target tersebut.

Pada saat terjadi peristiwa ToT, penutur pada dasarnya dapat membayangkan kosakata target, menyebutkan kosakata yang memiliki keterkaitan makna, mendeskripsikan fitur makna kosakata target, dan menyebutkan beberapa kosakata yang memiliki kemiripan bunyi. Hal ini menunjukkan bahwa proses mental penutur saat terjadi peristiwa ToT bekerja dalam dua area aktivasi, yakni area semantik dan area fonologis. Dalam hal ini, area semantik kosakata target sudah jelas, sedangkan kode fonologis gagal diaktivasi atau hanya dapat diingat sebagian (Ecke 2009, 185).

Paparan di atas menguatkan Teori The Tranmission Deficit Model oleh Burke (Schwatz 2002, 50). Menurut teori tersebut, penyebab tip of the tongue adalah adanya defisit dalam transmisi hubungan antara memori semantik dan memori fonologi sebuah kata. Maksudnya adalah ketika representasi sematik sebuah kata diaktifkan, pengaktivan itu gagal melampaui keseluruhan representasi fonologinya. Oleh karena itu, unit fonologis yang muncul bukanlah yang semestinya namun hanya bagian-bagian tertentu yang serupa.

Dalam pada itu, peristiwa ToT acapkali disertai proses mental kemunculan bahasa ibu dan/atau bahasa antara. Hal itu sejalan dengan pandangan Ecke \& Hall $(2012,735)$ yang menyatakan bahwa ToT terjadi karena gesekan bahasa dan pada penutur tiga bahasa atau lebih, pola gesekan antarbahasa tersebut menjadi lebih kompleks. Berdasarkan hal itu, 
penutur dua bahasa atau lebih mengalami gesekan bahasa (language attrition) saat hendak mengucapkan suatu kata sehingga penutur tersebut mengalami ToT. Berkaitan dengan hal itu, Ecke dan Hall (2012, 735) menjelaskan bahwa gesekan bahasa, dipahami sebagai pengurangan atau penyederhanaan sistem bahasa dan atau gangguan akses ke bahasa tersebut, diasumsikan sebagai aspek perkembangan bahasa yang normal dan seringkali tak terhindarkan dalam pengalaman berkomunikai seorang penutur bilingual atau multilingual. Gesekan bahasa tersebut dapat dialami ketika penutur sedang fokus mempelajari satu bahasa, sedangkan bahasa lain yang telah dikuasainya menjadi berkurang intensitas penggunaannya. Lebih lanjut, Ecke \& Hall $(2012,744)$ menjelaskan ToT juga berkontribusi pada dua asosiasi leksikal, yakni asosiasi leksikal dalam bahasa kata target (yaitu untuk mencari target dalam bahasa yang sama) dan asosiasi leksikal antarbahasa (yaitu untuk mencari target dalam bahasa yang berbeda). Asosiasi leksikal terjadi pada proses mengingat kata yang hendak diujarkannya dengan cara menghubungkannya dengan kata-kata lain yang memiliki keterkaitan dengan kata yang dimaksud.

KESIMPULAN Berdasarkan temuan penelitian yang telah disampaikan, tip of the tongue terjadi pada hampir semua kelas kata, yaitu nomina (42\%), verba (24\%), ajektiva (21\%), konjungsi (8\%), dan numeralia (5\%).Sebagian besar tip of the tongue merupakan efek kekeliruan yang muncul dalam tuturan dengan diiringi senyapan.Deskripsi fitur makna kosakata target direalisasikan dalam bentuk gestur. Proses mental tip of the tongue terjadi dalam beberapa tahap, yaitu (1) penutur memiliki gambaran objek dalam benaknya, (2) aktivasi set semantik ketika kosakata yang aktif adalah yang memiliki keterkaitan makna dengan makna kosakata target, (3) aktivasi medan makna ketika penutur mendeskripsikan medan maknanya, (4) aktivasi set fonologis ketika kosakata yang muncul dalam benak penutur adalah kosakata-kosakata yang memiliki kemiripan bunyi, dan (5) kemunculan bahasa pertama dan atau bahasa antara. Penelitian berikutnya dapat mengkaji ToT secara lebih mendalam berkaitan dengan kontribusi topik dalam kemunculan ToT dan strategistrategi yang dapat digunakan penutur untuk mengatasi hambatan produksi tuturan dalam ToT. Di samping itu, dapat pula dilakukan penelitian ToT dengan menggunakan teori dan metodologi yang berlainan sehingga pada akhirnya dapat menjadi sebuah khasanah penelitian ToT yang utuh.

Hasil penelitian ini dapat berkontribusi dalam pelaksanaan pembelajaran bahasa Indonesia bagi penutur asing, khususnya dalam keterampilan menyimak dan berbicara. Karakteristik ToT dan proses mental ToT yang ditemukan dalam penelitian ini dapat dijadikan bahan dalam melakukan inovasi pembelajaran, seperti model pembelajaran, bahan ajar, dan media pembelajaran. Hal itu bertujuan membantu pemelajar BIPA dalam menghindari dan meminimalisasi kendala produksi bahasa secara lisan, khususnya ToT.

DAFTAR PUSTAKA Afrilia, LK. 2015. "Tip of the Tongue pada penutur Indonesia: Implikasi terhadap Model Akses Leksikal". Jurnal Universitas Indonesia

Calabi, Clotilde. 2016. "Ancona? Aha! That's Her Name! Tip-of-The-Tongue Experiences". Analysis, 76 (4): 409-418. https://academic.oup.com/analysis/articleabstract/ $76 / 4 / 409 / 2624116$

Ecke, Peter. 2004. "Words on The Tip of The Tongue: A Study of Lexical Retrieval Failures in Spanish-English Bilinguals". Southwet Journal of Linguiatics, 23 (2): 33-63 
Ecke, Peter. 2009. "The Tip-of-The-Tongue Phenomenon as A Window on (Bilingual) Lexical Retrieval". In Anita Pavlenko (Ed.) The Bilingual Mental Lexicon: Interdisciplinary Approaches, 185-208. Bristol: Multilingual Matters

Ecke, P, \& CJ. Hall, 2013. "Tracking Tip-of-The-Tongue States in A Multilingual Speaker: Evidence of Attrition or Instability in Lexical Systems?" International Journal of Bilingualism, 17(6): 734-751. https://journals.sagepub.com/doi/abs/10.1177/136700 6912454623

Fernandez, Eva M. \& Helen Smith Cairns. 2011. Fundamentals of Psycholinguistics. West Sussex: Wiley-Blackwell

Gianico-Relyea, JL, \& J. Altarriba. 2012. "Word Concreteness as A Moderator of The Tipof-The-Tongue Effect". The Psychological Record, 62 (4): 763-776. https://link. springer.com/article/10.1007/BF03395834

Gollan, TH \& Silverberg, NB. 2001. "Tip-of-The-Tongue States in Hebrew-English Bilinguals". Bilingualism: Language and Cognition, 4: 63-83

Hodairiyah, \& Faris Febri Utama, 2019. "Bentuk-bentuk Kalimat Imperatif Permintaan pada Iklan Rokok 'Djarum 76'"'. Leksema: Jurnal Bahasa dan Sastra, 4 (1): 11 -20

Kozlovskiy, SA, SD. Shirenova \& AK. Neklyudova. 2017. "Brain Mechanisms of The Tip-ofThe-Tongue State: An Electroencephalography-Based Source Localization Study". Psychology in Russia, 10 (3): 218-230. https://cyberleninka.ru/ article/n/brainmechanisms-of-the-tip-of-the-tongue-state-an-electroencephalo graphy-basedsource-localization-study

Pangesti, Fida. 2014. "Fenomena Senyapan: Studi Kontrastif terhadap Tuturan Terencana dan Tuturan Spontan". In: International Seminar Language Maintenance and Shift IV. ISSN: 2088-6799. 18 November 2014. Semarang: Hotel NEO

Pinet, S. \& N. Nozari. 2018. "Twisting Fingers": The Case for Interactivity in Typed Language Production". Psychonomic Bulletin \& Review, 25 (4): 1449-1457. https://link.springer.com/article/10.3758/s13423-018-1452-7

Prihatini, Arti. 2019. "Semantic Network of The Word Association in the Field of Law". Litera, 18 (3): 430-446

Radel, Remi \& Marion Fournier. 2017. "The Influence of External Stimulation in Missing Knowledge Retrieval". Memory, 25 (9): 1217-1224. https://www.tandfonline. $\mathrm{com} / \mathrm{doi} / \mathrm{abs} / 10.1080 / 09658211.2017 .1282519$

Rahman, Azkia Rostiani, Kushartanti \& Harwinta Juhria Anjarningsih. 2017. "Tip of The Tongue Analysis in Indonesian Language Speaker: A Case Study". People: International Journal of Social Science, 3 (3): 292-300. (Online). $\mathrm{http}: / /$ creativecommons.org/ licenses/by-nc/4.0/

Schwartz, BL. 2008. "Working Memory Load Differentially Affects Tip-of-The-Tongue States and Feeling-of-Knowing Judgments". Memory \& Cognition, 36 (1): 9-19. https://link.springer.com/article/10.3758/MC.36.1.9

Schwartz, BL. 2010. "The Effects of Emotion on Tip-of-The-Tongue States". Psychonomic Bulletin \& Review, 17 (1), 82-87. https://link.springer.com/article/ 10.3758/PBR. 17.1.82

Singleton, David. 2000. Language and The Lexicon: An Introduction. London: Arnold

\section{Copyright @ 2020 Leksema: Jurnal Bahasa dan Sastra}


212 Leksema: Jurnal Bahasa dan Sastra Vol. 5 No. 2 